\title{
The Structure of Explanations and Counter-Explanations of Homosexuality
}

\author{
Fabrizzio Mc Manus \\ Laboratory of Social Studies of Science, Faculty of Sciences, Universidad Nacional Autónoma de México, \\ Mexico City, Mexico \\ Email: FabrizzioMc@yahoo.com
}

Received July $27^{\text {th }}, 2012$; revised August $28^{\text {th }}, 2012$; accepted September $12^{\text {th }}, 2012$

\begin{abstract}
The aim of this paper is to revisit an ongoing controversy within the so called "Science Wars"; more specifically, I will address a particular topic within the "human nature" debate: the ontological and epistemological status of homosexuality. I claim that, in this particular chapter of the "Science Wars", we are continually left in an explanatory impasse even when more data are collected, more rigorous experimental techniques are developed, more subtle arguments are offered and more pluralistic narratives are told. My diagnosis of the source of this impasse leads me to the conclusion that here we are dealing with a structural problem that cannot be solved with an elaboration of new models and theories that maintain an ontology and an epistemology that are no longer suited as an explanans of human nature in general, and homosexuality in particular. Nevertheless, my analysis of the structural features of the biological explanations and the constructivist counter-explanations also leads me to the belief that, although biologists do not fully understand the intricacies of subjects, neither constructivists understand the facticity of evolution and the challenge that it implies. If so, then the subject might be the right target of explanation. And, if so, constructivists might be right about the uniqueness of human homosexuality as a modern, western phenomenon explainable in terms of subjectivities and identities that mold and are molded by desires and institutions. But, if they are, evolution is not expendable because now we are facing a most intriguing question: How is that we humans became subjects?
\end{abstract}

Keywords: Homosexuality; Human Nature; Philosophy of the Subject

\section{Introduction}

The aim of this paper is to revisit an ongoing controversy within the so called "Science Wars"; more specifically, I will address a particular topic within the "human nature" debate: the ontological and epistemological status of homosexuality-or, should I say human homosexuality?

On the one hand, biologists, psychologists and physicians have attempted to explain homosexuality as a biological phenomenon caused by biological forces. These biological forces are sometimes catalogued in terms of proximate and ultimate causes, following in this Mayr's classical dichotomy (Mayr, 1993); proximate causes can also be subdivided in terms of internal vs external forces, although this second dichotomy is problematic and seldom used.

Proximate (internal) causes are usually bio-molecular mechanisms or developmental pathways present in specific individuals (Hamer et al., 1993; Hamer, 1995; Hu et al., 1995; LeVay, 1991; LeVay \& Hamer, 1994; Pillard, 1997; Rahman \& Wilson, 2003; Savic et al., 2005; Savic et al., 2008; Swaab et al., 2001; Yamamoto et al., 1996); proximate (external) causes are usually environmental phenomena, such as pollutants or maternal effects, that act as developmental insults capable of disrupting canalized developmental pathways that in "normal" circumstances produce a "normal" trait: an heterosexual sexual orientation (see chapter 6 at Poiani, 2010). Ultimate causes are, in contrast, evolutionary forces such as sexual selection, group selection, kin selection or even genetic drift, all of these acting on populations
(Hutchinson, 1959; Kirby, 2003; Muscarella et al., 2001).

But not all biological explanations of homosexuality are always so dichotomic. In the last twenty years different approximations to biology in general, and to evolution in particular, have produced explanations that not only criticize the very dichotomy of proximate vs ultimate causes-I have in mind approaches such as Developmental Systems Theory (DST) (Griffiths \& Gray, 1994; Oyama et al., 2001) and Evolutionary Developmental Biology (Evo-Devo)-, but also the idea that there are species-specific mechanisms responsible for making an individual homosexual. The works of Joan Roughgarden and Aldo Poiani, although very different in their details, point to new explanations that de-essentialize homosexuality as a biological explanandum by conceiving it as a multiply realizable phenomenon. This leads to new and interesting scenarios in which cooperation and agency (Roughgarden, 2004, 2009) and behavioral and neuronal plasticity (Poiani, 2010) become more important elements for any biological explanation of homosexuality.

On the other hand, philosophers, sociologists, anthropologists and literary critics have resisted these explanations and have advanced a collection of what I call counter-explanations (Byne, 1994; DeLamater \& Hyde, 1998; Fausto-Sterling, 2000; Roof, 1992; Rosario, 1997). Counter-explanations are not alternative explanations although there is a myriad of alternative explanations emanating from these disciplines.

Instances of alternative explanations are: 1) the family of constructivist approaches that encompass psychoanalytical and 
psychodynamic explanations (e.g. Dean \& Lane, 2001); 2) the sociological models that focus on social roles and thick and thin descriptions of actions and signified traits that constitute gender (Dickinson et al., 2003; Prieur, 2008); 3) or, even, the Queer Theory approach centered upon performative speech acts, practices of embodiment and intercorporeality, and the interaction between agency and structure in the conformation of modern subjectivities in terms of identities (Butler, 1993; Sullivan, 2003; Weiss, 1999).

But these are NOT counter-explanations although they might contain elements of them. Let me elaborate, then, this distinction a little further. Biological explanations have produced a universe of data that in principle are evidence in favor of the biological nature of homosexuality. These data cannot simply be ignored, they have to be counter-explained and that is exactly what counter-explanations do: they explain away these data.

In a sense alternative constructivist explanations require counter-explanations for two different reasons. First, counter-explanations question the objectivity and validity of the datadriven biology by means of a dialectic deconstruction of the subject-object relationship that seeks to show how cultural biases are projected upon these data. Second, this dialectic deconstruction also questions an implicit axiom regarding causation that informs all biological explanations; this axiom usually takes the form of an implicit commitment towards an ontology of homosexuality in which homosexual subjects possess homosexual bodies that are a type of causally structured body.

I will elaborate on the details of this axiom later but I would like to point out that by bringing this axiom into question it is possible to problematize the very notion of causation that underpins biological explanations and, hence, to offer alternative explanations that emphasize subjectivity, identity, psychodynamics and cultural contexts as more relevant elements for any account that attempts to understand homosexuality.

Nevertheless, counter-explanations and alternative explanations run the risk of dematerializing the homosexual subject or, at least, to conceive his or her materiality only in terms of signified bodies nested within networks of practices, actions and meanings. The risk of course is not only theoretical but also ethical and political. This is so because resisting biological determinism, essentialism or some mild forms of evolutionary ideologies (Marks, 2012) should not take us into an allegiance with creationism or intelligent design. We are, after all, evolved beings and that is a fact that matters.

And this fact matters because if, at the end of times, a Peircean community of scientists decides that constructivist alternative explanations are right, a fundamental question is going to arise: How an evolved animal became capable of being a subject? A subject capable of performing speech acts, endorsing identities, possessing an agency, being molded by a structure, etc.

Surprisingly this question takes us to an old branch of philosophy and a very new branch of biology. As Fernando Vidal (2006) has shown Anthropology used to be understood, at least in the XVIII century, as the branch of metaphysics that deals with the problem of what is to be a human. But now some evolutionary biologists have begun to think about the evolved cognitive and emotional complexity of human beings. A few have even suggested the necessity of a new approach which has been labeled as "Evolutionary Social Constructivism" (Wilson, 2005). Poiani's explanations go some steps further in the right direction, if I might say so, but they are still prone of counter-explanations.

And this should raise an eyebrow for philosophers of science.
What is going on in this particular chapter of the "Science Wars" that continually leaves us in an explanatory impasse even when more data are collected, more rigorous experimental techniques are developed, more subtle arguments are offered and more pluralistic narratives are told. Why biology is still seen by constructivists as a form of essentialism even after biology itself has fought hard in order to overcome an essentialism of species (Hull, 1965) and traits (Rieppel, 2005) and has even reinvented itself as DST and Evo-Devo exemplify. Why constructivist themselves fail to see this fact that matters: an evolved animal that became a subject. And why constructivism is still seen by many biologists as mumbo-jumbo jargon incapable of explaining anything.

My hypothesis, and the main objective of this paper, is to advance as an answer the possibility that we are dealing here with a problem that lies outside the data, the techniques and the particular arguments and lies in the very structure of the explanations and counter-explanations offered so far. Maybe the problem is structural and cannot be solved with an elaboration of new models and theories that maintain an ontology and an epistemology that are no longer suited as an explanans or counterexplanans of human nature in general, and homosexuality in particular.

In order to elaborate such an argument this paper is divided in four sections. The first section tackles with some structural elements present in most biological explanations of homosexuality. The second section, on the other hand, analyzes structural elements of the counter-explanations. The third section is dedicated to the problem of the evolved subject and should be understood as an attempt to bridge this explanatory impasse or, at least, to show why it eventually must be bridged. Finally, the fourth section presents the conclusions of this paper.

\section{Structural Elements of Biological Explanations}

Maybe two of the most famous biological explanation of homosexuality nowadays are, first, the infamous and hypothesized gene on the q28 section of the X chromosome (Hamer et al., 1993) and, second, the equally famous and assumed dimorphism in the third Interstitial Nuclei of the Anterior Hypothalamus (INAH3) (LeVay, 1991). But biological explanations are much older than genetics and neurosciences and we could argue that they actually date back to the XIX century and, even when they are stated in terms of the modern theory of evolution (the so called New Synthesis), they date back to the late 1950s (Hutchinson, 1959).

So, this background indicates that our domain of interest encompasses 150 years in which biology has experienced fundamental changes more than once. At first sight this might takes us into the belief that very few elements, if any, can be identified as conserved structural features constitutive of these explanations. In this section I will show that, these changes notwithstanding, there are such elements.

The first element that I would like to consider as a conserved structural feature has to do with the most basic strategy for classifying living beings in biology, at least since the XVIII century: seeking for homologies (or affinities, as they used to be called prior to the mid-XIX century). There are many definitions of homology and some actually pre-date Darwinism but the core of the concept has to do-now-with a similarity among organisms of the same or different species caused and explained by common descent. 
Examples of this way of thinking about homosexuality abound. For example, Bruce Bagemihl (1999) has compiled an entire book of cases of non human homosexuality, transexuality, intersexuality and trasvestism. Yamamoto and co-workers (1996) have tried to use Drosophila as a model organism for finding the specifics of the bio-molecular mechanism that produces homosexual behaviors not only in flies but maybe also in humans; Frank Beach (see Fausto-Sterling, 2000) used a very similar approach with mice ca. 1940s although under a less mechanistic view of behavior. Even Roughgarden and Poiani seem to assume that homosexuality in humans is, in a sense, an instance of the same kind of explanandum as homosexuality in different species of birds and mammals.

But these authors are not alone. Evolutionary explanations also assume that homosexuality in humans is an instance of a type of phenomena that encompasses several taxa and so should be explained in similar terms across all of them, notwithstanding if these terms invoke kin selection, group selection or other evolutionary forces.

And historically speaking XIX century biology was not very different (see Rosario, 1997 and the rest of the papers in the book). Most sexologists invoked pseudo-Haeckelian explanations of homosexuality that involved phylogenetic atavisms or degenerations that led into more primitive behaviors; hence, they assumed that homosexuality was comparable to other animal behaviors. Legal medicine, even in the XX century, still continued to use that framework as can be shown with the paradigmatic case of the spanish endocrinologist Gregorio Marañon (1960; see also Ferla, 2004).

What is common to all of these explanations is what I have previously named "an empiricism regarding sex and gender categories” (Mc Manus, 2010, in press) that basically implies a commitment towards a westernized and modern view of sexuality in which variables such as 1) sex; 2) gender; 3) sexual orientation-understood in terms of the gender of the intended object of desire; 4) stereotyped physical appearances and 5) stereotyped behaviors are considered sufficient to describe all forms of what we, in the West, call "sexuality"; at the same time, it implies a rejection of the relevance that the phenomenological dimensions in which these categories are actually lived and experienced by human beings might possess.

This implies a commitment towards the universality-cultural as well as interspecific - of these variables not only in terms of their mutual independence but also in terms of their capacity to generate a theoretical multi-space in which every animal sexual behavior can be mapped-as the book of Bagemihl perfectly illustrates.

In other words, what these explanations have in common is the idea that sexuality corresponds to a family of traits in which sexual orientation can be conceived as a particular trait homologous among different animals and with different character states that correspond to what we in the West call "homosexuality", "heterosexuality" and "bisexuality" (this corresponds to what I have labeled as models of taxonomic identity [Mc Manus, 2009]).

These similarities, as all homologies, could then be understood as structural similarities in the organization of the archetypes of organisms (Baupläne) and so similarities due to common descent. This will make homosexuality a trait comparable with classical instances of homologies such as the arms of humans and apes, the wings of insects and the gills of crustaceans, the seeds of coniferous and flowering plants, etc.
Nevertheless, the concept of homology is not an easy one to grasp. This is so because the concept of the archetype flourished in the german tradition of biology and, as it is well known, this tradition was deeply influenced by Kant. But already in the XIX century biologists abandoned a strictly kantian epistemology re-tooling in the way the very concept of homology.

I will sidestep the many intricacies of the concept as well as its history but I would like to point out that archetypes are not entirely dead in biology. The discovery of the Hox genes in a sense revitalized the idea that there is a sort of archetype codified in the genome. More recently, Evo-Devo has attempted to expand this notion by talking about developmental pathways and phylotypic stages causally responsible of producing form (Striedter, 2004).

Anyway, the idea of behavioral homologies has its own history (Hebb, 1953; Rendall \& Di Fiore, 2007) and it is quite a history. On the one hand, the very possibility of talking about behavioral homologies has been disputed because, for many scholars, behavior is tantamount to a functional dimension and so not prone to a structural analysis; on the other hand, for those who accept the possibility of behavioral homologies, it is still a matter of controversy if behavioral homologies could exist even when there are no structural underlying homologies. Again, I will sidestep these philosophical discussions and I will focus on the relevant consequences for our own topic.

The relevant aspect, conserved across 150 years of biology, has to do with the possibility of conceiving sexuality as a family of traits, in general, and sexual orientation, in particular, as a type of trait with many instances such as homosexuality, bisexuality and heterosexuality. The feasibility of hypothesizing that homosexuality might be an instance of a homologous behavioral trait helps us to understand several things. First, why we try to use the very same theory to explain homosexuality in humans and other animals. Second, why we seek for similar mechanisms underlying homosexuality across different species. Third, why many biologists that accept homosexuality as a multiply realized trait still consider it the same phenomenon even when it is generated by different causal mechanisms (if, of course, you accept that behavioral homologies can occur without an underlying morphological homology). Fourth, why the work of anthropologists is so easily discarded when they insist in showing the cultural differences regarding "sexuality"; this has to do, I might say in order to clarify the point, with the capacity of the concept of homology to make "the same" things that might appear very "different".

And this structural feature is by no means privative of the topic here revisited - explanations of homosexuality — as can be seen in the work of Paul Griffiths (2011) when he claims that human nature is variable but all variations can be accommodated within the framework of homology. This, in a sense, prohibits any new and culturally specific traits because all variation would be an instance of a rather general kind.

If we follow this argument the very concept of homology might allow biologists to conclude that no human behavior is truly unique because, even if it does not possess an homologue, it can at least be thought of as a field homologue of a family of behaviors that were precursors of our more complex and signified behaviors-i.e. not homologous to a particular behavior in non human animals but related to them because this human behavior developed by modifying and enriching these behaviors (Striedter, 2004).

The second structural feature I would like to characterize is an 
elaboration of what Joseph Rouse (1994, 2002) has identified as a form of pernicious philosophical naturalism quite common in cognitive science. He has labeled it as the problem of "the manifest necessity”. This problem is an heir of Wittgenstein's argument of following a rule (Rouse, 2002). However, this particular version of the problem arises when cognitive scientists (as third person knowers) seek to analyze norms, actions and meanings in terms of natural regularities or causes. In other words, whenever scientists try to ground normativity in causation -understood as a natural necessity.

Rouse claims, echoing Wittgenstein, that any analysis of normative phenomena-such as norms, rules, meanings or actionsdesigned under these lines will fail to explain these phenomena in terms of natural regularities. This is so because the scientist, as a third person knower, faces a finite amount of data-thus, his or her interpretations are epistemically underdetermined by evidence - and, so, is unable to discriminate among a myriad of possible causal mechanisms capable of producing these data.

For Rouse the only possible solution would be to assume that regularities manifest themselves-phenomenologically speaking-in such a way that the specific causal mechanism responsible for the observed regularities is transparent to the scientist as a third person knower. In other words, if we take causation to be a natural necessary regularity and if we attempt to analyze normative phenomena in terms of causation (both big if's), then the only way to overcome the underdetermination problem is to suppose that causation manifests itself in such a way that the third person knower correctly identifies the relevant causal mechanism responsible for the normatively guided actions that served as observations ${ }^{1}$.

Now, what is the relationship between this argument and the biological explanations of homosexuality? The second structural element is similar to the previous argument in two respects. First, usually the scientist, as a third person knower, tries to explicate the homosexuality of a subject as if this were a behavioral trait. But the funny thing is that homosexuality is conceived not only as a behavioral regularity but also as a disposition that normatively guides and sanctions the behavior of the subject; moreover, as the Kinsey scale illustrates (Fausto-Sterling, 2000; Mc Manus, 2010), homosexuality, even if constructed as a behavior, also has phenomenological dimensions like arousal, desire and fantasy. So, the first similarity lies in the fact that homosexuality is described at the same time as a normative phenomenon that possess phenomenological dimensions, on the one hand, and as a disposition responsible for the observed sexual and emotional behavior, on the other. In other words, homosexuality as a normative phenomenon is grounded in causation ${ }^{2}$.

Indeed, this ambivalence in the very ontology of what is ho-

\footnotetext{
${ }^{1}$ Wittgenstein's and Rouse's arguments are much more complex but I will sidestep a full exposition of them because this will not contribute to the general argument of the paper. If interested, the reader should review the problems associated to reglism and regularism as strategies that attempt to characterize norms in terms of regularities and how they lead to an infinite regress (I recommend reading the paper of King Dávalos, 2008, and some other contributions collected at Esteban \& Martínez, 2008).

${ }^{2}$ The idea that sex-generic categories, including sexual orientation, are normative has long been defended in Gender Studies and Gay and Lesbian Studies, at least since Foucault (1977). The phenomenology of these categories is usually taken as evidence of the normative dimensions of them because desire, arousal and fantasy not only guide behavior but also sanction behavior as enjoyable and pleasurable or disgusting and repelling. When understood as identities their normative dimensions are even stronger because the relation of belonging to a group impose a serious burden upon the subject.
}

mosexuality is fundamental for biological explanations because homophobia tends to preclude homosexual behavior in many cultures and because there are situations in which "situational homosexuality" is observed (e.g. prisons). Nevertheless, neither the lack of homosexual behavior in a subject counts as evidence against the hypothesis that he or she might be homosexual nor the behavior, when observed, verifies that he or she is actually homosexual.

This is so because the idea of a silent and dormant disposition helps to establish the supposed universality and transculturality of homosexuality. If this were a motto, it would be more or less like the following statement: "homosexuals are everywhere but they might not be visible in some cultures”. In opposition, the plasticity of behavior aligns itself with the homology-laden reading that makes "the same" things that are "different" because, if homosexual and heterosexual subjects can act as heterosexual or homosexual subjects-respectively-then behavior is plastic enough to be molded by cultural dimensions.

Second, "the manifest necessity" problem has also a related sibling in this field. We can see this when we analyze the way in which biological explanations of homosexuality connect causation with normativity. In Rouse's example the problem of the manifest necessity was a problem for the researcher because he or she did not have a direct access to the phenomenology of the norms and any attempt to characterize the norms in hermeneutical terms would imply a rejection of the very spirit of naturalism. But biological explanations of homosexuality usually employ subjects that manifest their sexual orientation to the researcher and so the previous problem is bypassed. This allows the identification of a possible causal mechanism that can be taken as the discovery of the natural necessity that manifests itself with transparency into the consciousness of the homosexual subject.

Let us illustrate this with an example. Simon LeVay and Dean Hamer (1994) combined their findings in order to offer a more robust causal narrative capable of explaining how genetic differences could produce a homosexual behavior. They basically endorsed the hypothesis that the genes in Xq28 might be responsible for the morphology of INAH3 and-through an argument mediated by homology which invoked the regulatory dimensions of INAH3 in the sexual behavior of mice-they claimed that this almost insignificant brain modification would produce a feminized behavior in males and, thus, it would make them homosexuals. Of course, these men would not be aware of the underlying morphology - the causative part of the storybut nonetheless it would modify their behavior by structuring in a feminized way their patterns of desire, arousal and sexual fantasy and so, eventually, their behavior. Hence, causation manifest itself transparently into the consciousness of the first person and so grounds a normative disposition.

At this point we could be tempted to conflate this problem with an impoverished view of causation. But we should not go that far. It is true that the previous example seems to accept without a question a bottom-up approach of how different levels of organization present in biological beings causally interact. However, a bottom-up approach to causation does not exhaust all biological understandings of biological causation, certainly not in evolution, development or molecular biology (Craver, 2007; Martinez \& Moya, 2011). More complex causal stories can be offered, as can be seen in the proposals of Roughgarden and Poiani. In the case of Roughgarden (2004), social interactions among different animals of the same species might produce 
alterations in behavior that have also morphological and physiological correlates. In the case of Poiani, the interactions among different levels of organization can also produce alterations in behavior.

But a more complex causal narrative is not tantamount to a rejection of a pernicious naturalism. All of these models still assume that the phenomenological dimensions of homosexuality in humans are causally produced by underlying mechanisms and so that homosexuality in humans, even if richer because of its meaningfulness, is still a homologue of homosexual behaviors in non human animals. All of these models still assume that these causal mechanisms will manifest themselves with transparency in the consciousness of the subject, making him or her homosexual.

Of course, the problem of underdetermination is still present because there is a myriad of biological mechanisms that could in principle produce that behavior but, at least, the problem of bridging causation and normativity seems to be solved. Also avoided is the problem of an infinite regress present in the original Wittgensteinian argument.

Curiously, this second structural element can be restated as a commitment to an ontological view on the causes of homosexuality in which homosexual subjects have homosexual bodies, i.e. their bodies are causally structured in a different form than heterosexual bodies. This does not imply a tension neither with the multiply realized view because these causal mechanisms might be different in different species or even organisms, nor implies a tension with the first structural element because, as I said before, behaviors can be homologues even if their underlying developmental pathways are not (a phenomenon known as developmental drift). And even if these behaviors were not homologues, they could still be thought of in terms of evolution if they happen to be similar solutions to similar problems: i.e. analogues.

However, I will go further in this analysis in order to claim that the first and second conserved elements actually act synergistically. This is so because, if homosexuality, understood as a normative phenomenon, for example, as an identity or subjectivity, can be grounded in causation, then, the existence of similar dispositions in non human species (similar up to a point, of course, because these disposition would most likely not possess the phenomenological correlates that they have in humans) might indicate the existence of similar mechanisms in those species and, so, would allow us to think it in terms of homology. And the synergy goes both ways because, if we assume that sexual orientation is a trait present in human animals and non human animals, then we, per force, would seek for explanations that do not invoke elements only present in humans, elements such as language, meaningful actions, subjectivities, etc.

\section{Structural Elements of Counter-Explanations}

For many biologists the accusations of essentialism are, to say the less, puzzling. For them, constructivists cannot seriously believe that modern evolutionary biology resembles classical Aristotelian or Platonic doctrines of essences. Moreover, modern biology emphasizes variation and demographic thinking, boundless and endless changes in morphology, physiology and behavior - even if we accept that not every point in the morphospace can be occupied by living beings.

Evolutionary theory implies that organisms co-evolved with their environments and, so, that they lack intrinsic properties because everything — adaptation or constraint-they exhibit is a relational property; every trait is the result of previous cycles of change with modification in an environmental context.

But in light of the elements described in the first section of this paper we can understand why constructivists accuse biologists of essentialism. The idea that, notwithstanding how much change we detect, a behavior is still the same behavior, in the sense of being a homologous behavior (or an analogous behavior and so the same solution to a similar situation), and that it is the result of a causal mechanism that manifest itself in the consciousness of human subjects, resembles essentialism enough in its transhistoricity to justify the label. But it does not resemble essentialism enough to be equated with fixism or univocal realizability. And this last point is fundamental because classical essentialisms will not admit the identity of essences when there is a serious possibility of endless and boundless variation, on the one hand, and a multiplicity of causal pathways capable of producing the same phenomenon, on the other hand.

I believe this helps to explain, at least partially, why we are stuck in an explanatory impasse. Biologists fought against essentialism understanding it as species (and traits) fixism and univocal realizability. Constructivists went a step further and fought against the trans-historicity implicit in the homologation of different culturally-laden phenomena that were interpreted as the same.

But this last point is only one of the structural features of counter-explanations. There are at least two more elements that I advanced in the introduction of this paper. Both emerge from a dialectic deconstruction of the subject-object relationship but, on the one hand, one horn of the criticism refers to the limits of objectivity while, on the other hand, the second horn refers to the implicit axiom of a causally structured homosexual body.

At this point it might be important to clarify one thing before getting started. I am the one who reads most counter-explanations as offering a dialectic deconstruction of the subject-object relationship; the authors I will revisit did not necessarily employ this terminology. Nonetheless, the idea of framing the counterexplanations in these terms occurred to me when I read some criticisms exposed by Donna Haraway (1989) against the primatological research on the supposed heritable nature of intelligence; what I saw in her criticism was a general feature of some counter-explanations regarding human nature. With this in mind I will proceed by examining a couple of examples.

Example No. 1: When Simon LeVay claimed that he had found a dimorphism in the hypothalamus of men Judith Roof (1992) counter-explained his findings by arguing that he was projecting onto the data the very dynamics of exclusion and invisibility that were definitory of the political vulnerability of lesbians (and, I will add, other subaltern sexualities). According to Roof, lesbians were discriminated by men because they were women and they were also discriminated by heterosexuals because they were homosexuals but, worse, they were discriminated by gay men because the latter still exerted a privileged male-centered view that subordinates and excludes women, including lesbians.

So, Roof interpreted LeVay's explanation as an erasure of lesbianism as an explanandum because LeVay's model was only capable of explaining male homosexuality and was, as a result, incomplete. Moreover, LeVay's naturalization of homosexuality redeemed gay men but not lesbians as a part of nature; and, as Roughgarden once said, the right to feel as a part of nature, as belonging to the natural order, has important psychological 
effects on the Self (2004). Male homosexuals in the work of LeVay were the result of a naturally occurring causal mechanism and, so, could not be conceived as morally vicious but the same could not be said about lesbians.

Roof offered other arguments against LeVay's hypothesis but the previous one is interesting for the following reason. It accuses a researcher of inadvertently projecting his cultural biases onto the data in order to use those data to validate his own privileged position as a subject, in this case, as a gay man.

Example No. 2: INAH3 is not the only brain region that has been hypothesized as causally responsible for the generation of homosexual behaviors in humans. The Corpus Callosum (CC) is another famous brain structure that has been considered a possible candidate for causing behaviors such as homosexuality and gender identity disorders. Indeed, this explanation was criticized by Anne Fausto-Sterling (2000) in her book Sexing the Body. Fausto-Sterling offered an elaborate argumentation against these data by showing how the Corpus Callosum was, at the same time, a mathematical, material and literary object.

For her, it was important to show that the CC was material and mathematical because both are aspects of scientific objectivity. Much has been written in philosophy of science about objectivity (Daston \& Galison, 2010; Kuhn, 1977; Longino, 2002) but now it is more or less widely recognized that this concept encompasses several aspects. For example, there is the procedural side of objectivity connected with the standardized techniques and mathematical tools that allow us to model natural phenomena by abstracting and extracting them away from their original contexts of occurrence in order to produce what Latour (1992) calls immutable and combinable mobiles.

These mobiles are an instance of a circling reference (Latour, 1999) that functions as evidence in support of some particular hypothesis by establishing their accuracy and, so, they exemplify a different aspect of objectivity: representing nature. But they are also associated with a third aspect of objectivity that grounds an interpretation of objectivity as inter-subjectivity: the replicability of observations. These mobiles result from standardized procedures that in principle warrant the cancellation of idiosyncratic biases by ensuring that any subject might be able to reproduce those results.

In my view Fausto-Sterling concentrated so much in these elements because it is a disservice to criticism to ignore the methodological intricacies of science as well as its sociological complexities; to accuse scientists of projecting their biases upon data without even analyzing their methodologies and the sociological processes of mutual validation is not only risky but also is the best way to generate a conundrum in which both sides of the dispute end up with a philosophical deafness hard to overcome.

Nevertheless, Fausto-Sterling understood something that some philosophers of science have found hard to assimilate. The task of philosophy should not be to serve as an unconditional defender of science but, on the contrary, to criticize it when it claims more than it can prove. The other side of her argument showed that the CC was a literary object because the causal narrative offered by physicians, biologists and psychologists is still a narrative that situates within a background the empirical findings and connects them in order to articulate an integrative explanation of the phenomenon in question.

In a sense, Fausto-Sterling engaged in an informed criticism that situated the scope of these results by emphasizing the complex materiality of the CC. On the one hand, the materiality of the CC is the materiality of the body and so it is connected to the causal arrangements that underlie behavior. On the other hand, it is the materiality of evidence; but a piece of evidence is not tantamount to a piece of the body because the evidence is produced through a set of standardized techniques and procedures that translate a tridimensional living body into bidimensional sections of a corpse or, more correctly, that translate bidimensional sections of a corpse into the inferred structure of a tridimensional living body.

And this process of integrating different sets of evidence and interpreting them is still prone to cultural and systemic biases and, in some cases as Fausto-Sterling showed, to blatant methodological errors. In the particular case of the CC, distinguishing between the typically male and the typically female morphs of the CC was controversial not only because there was no standardized technique for doing it but also because it was done without specifying clear cut criteria that guided the construction of this taxonomy. Claiming that sexual orientation or gender identity resulted from the presence of a typically female morph in males or a typically male morph in females was dubious because the underlying classification was dubious. If this hypothesis was accepted, wrote Fausto-Sterling, was not because of the merits of the research but because it confirmed a cultural and systemic bias: gay men and Male to Female Transexuals (MTF) are just feminized men and lesbians and Female to Male Transexuals (FTM) are just manly women.

Anyway, both cases exhibit a common structure already anticipated in the introduction. In both situations we find a criticism that deconstructs the supposed validity and objectivity of the evidence and the causal narrative erected upon it through a dialectic analysis of the relationship between the subject-the scientist and the object-the data.

More exactly, in both cases the criticism targets this implicit dialectic that arises as a consequence of the demands of objectivity upon the researcher. This is so because objectivity is understood as an ethical and epistemic neutrality in which the values, goals and expectations of the scientist should be cancelled in order to avoid any interference. The standardized techniques, the mathematical tools and the replicability and intersubjective accessibility of the data should grant the veracity of the results.

Hence, this produces an inversion of positions in which the scientist transfers to the data his or her own position as a subject. And so, the data are in principle "telling us their truth"; they occupy the structural place of the subject because they enunciate what is the case. But this enunciation is only possible because the experimental settings stabilized-through standardized procedures, mathematical models and theoretical interpretationsthe possible outcomes of the experiment. In other words, the object as a subject tells its truth in the vocabulary of the subject as an object because the latter transferred not only his or her position but also made possible the capacity of enunciation of the former by generating a context free of interference in which it can tell us its truth in a language we can understand.

Moreover, what is the case and what is the truth is the case about some human subjects, is the truth of some human subjects. This makes the subject (the homosexual subject in this instance) the object of enunciation. As structural positions, the subject becomes the enunciated object and the object becomes the enunciating subject.

Sadly, at this point homosexuality is naturalized and the procedural dimensions of objectivity that brought into being and kept the stability and immutability of these combinable mobiles 
are usually taken as a disposable ladder. The literary dimensions of these mobiles are forgotten and they are reified as causal mechanisms (Winther, 2006, 2009). Statistical correlations are read as causal relations, socially constructed taxonomies are read as natural kinds and local experimental findings are taken as robust and trans-historical regularities.

But this is only half of the story. This is so because humans tend to mold their behaviors and identities according to the available descriptions of themselves - as Hacking (2001) has famously claimed by labeling this process a "looping effect of human kinds". The funny thing about this looping effect is that it might produce, in some but not all cases, a more stereotyped behavior. Thus, the subject reclaims a subjectivity apparently enunciated by the object and, so, the hermeneutical circle finishes with a subject fully convinced of the naturalness of his or her subjectivity.

Precisely because of this last point counter-explanations are usually the first element of constructivist alternative explanations. They counter-explained the data and restored the complexity of the subject and, therefore, advanced the possibility of searching for a different type of explanation.

\section{Towards a Truly Evolutionary Social Constructivism}

But there is this fact that matters: we evolved. We know we are subjects and we also know that bacteria are not subjects, protozoa are not subjects, plants and fungi are not subjects, sponges are not subjects (sponge Bob notwithstanding), worms are not subjects and, about apes and some mammals, well, we are not so sure anymore although for centuries we would have said that they are not subjects.

And, by subjects, I mean that we are aware of our own environment and about ourselves, even of our own awareness of being aware, but I also mean that we are capable of acting according to goals, desires and norms. We are subjects because we can be held accountable for our actions-we can be ethically and epistemically responsible and, so, we are not merely responsive, but we can also be subjected by institutions created by our intentionality, by our capacity to know that the other knows that we know; hey, we can promise! We are subjects because we are capable of acting as a collective because we can share-mainly through language-our goals and means to achieve those goals, but we are also subjects because we can exert power upon others through those institutions; we can let them know things that will alter their behavior, we can even menace or threaten them (Habermas, 1999; and Schmitt, 2004, elaborate on some of the previous points).

This is exactly what allows us to have a world, to have a culture, because, in Heideggerian terms, the subject is a Dasein, it does not possess properties but existentiaries as forms of being-in-the-world (Heidegger, 1927). But, surprisingly, this apparent difference might be the reason for taking evolution more seriously, as Derrida advanced in The animal that Therefore I am (2008) when he concluded that, even if stones are Weltlos (without a world) and most animals are Weltarme (poor in world), evolution is still fundamental because our capacity to be a Dasein must have evolved from a previous condition of being poor-in-world. Derrida himself criticized philosophers, specifically continental philosophers, for ignoring the fact that we evolved.

If so, then the subject might be the right target of explanation.
Constructivists might be right about the uniqueness of human homosexuality as a modern, western phenomenon explainable in terms of subjectivities and identities that mold and are molded by desires and institutions. But, if they are, evolution is not expendable because now we are facing a most intriguing question: How is that we humans became "evolutionarily" and become "developmentally" subjects?

Such a change in the explanandum is not necessarily disruptive to the research programs of physicians, psychologists and biologists. After all, as Millikan (1984) has shown in the case of explanations of adaptations, sometimes we misidentify the target of an explanation and attempt to explicate what results to be a mere consequence of a more interesting and fundamental phenomenon. For example, we might try to explicate why the structure of our hands is an adaptation for writing but, if we do this, we have trans-historicized writing and misidentified a more interesting and fundamental phenomenon: the capacity of our hands to handle objects with an incredible precision and eyehand coordination. Similarly, if homosexuality is explained in constructivist terms, then the more interesting and fundamental phenomenon is our capacity to become subjects.

Cognitive scientists, neurophilosophers and biologists have already begun research programs that might be able to tackle some parts of the previous question. Kim Sterelny, for example, is interested in the evolution of agency, desires and intentionality (2001); according to him intentionality arises in epistemically translucent environment (examples of environments such as these are social environments or highly heterogeneous environments) in which there is no singular robust environmental clue and, so, it is more adaptive to triangulate different and independent environmental clues in order to know what are the exact environmental conditions and how we might proceed in such scenario. Social environments are an instance of this kind of scenario because a conflict of interests might arise among different organisms which may lead to cheating. Desires, on the other hand, evolved in order to help the organism to ponderate which activities should be a priority.

Sober and Wilson (1998) is another good example of this new trend in biology. They are interested in the evolution of sociality and normativity. Wilson in particular has advanced the above cited "Evolutionary social constructivism" but, sadly, he has framed it in light of classical population genetics (Wilson, 2005). This is unfortunate because he understands plasticity only in terms of norms of reactions, i.e. as the capacity of a genotype to produce different phenotypes in different environments. This seriously restricts the scope of his proposal because it still implies a commitment with a view on phenotypic traits in which they are always the expression of an underlying genotype.

In that regard, Poiani is probably the biologist that has better understood the challenges posed by constructivists. Although his proposal is prone to counter-explanations because it still tries to explain homosexuality not as a consequence of being subjects but as a homologous trait present in humans and nonhuman animals, it nonetheless emphasizes the plasticity of the brain without reducing this property into a norm of reaction. For him, plasticity encompasses the flexibility of a trait that is not entirely canalized either environmentally or genetically. Thus, plasticity implies cultural evolvability - the capacity of a system to undergo evolution, i.e. to change- - because a plastic system-like the human nervous system-can react towards novel situations by modifying these situations or by adapting itself into these situations. 
We are certainly at the dawn of these alternative forms of doing biology. Current research is too much gene-centered but cognitive sciences might achieve, if they embrace the constructivist challenge, the possibility of representing human nature not as the negation of our cultural complexity but as what grants us that very cultural complexity. This will imply a rethinking of the very structure of modern explanations of homosexuality and human nature; rethinking also the constructivist challenge. We might only hope.

\section{Conclusion}

In this paper I revisited an ongoing controversy within the so called "Science Wars": the epistemological and ontological status of homosexuality. I claimed that, in this particular chapter of the "Science Wars", we are continually left in an explanatory impasse even when more data are collected, more rigorous experimental techniques are developed, more subtle arguments are offered and more pluralistic narratives are told.

My diagnosis of the source of this impasse led me to the conclusion that here we are dealing with a structural problem that cannot be solved with an elaboration of new models and theories that maintain an ontology and an epistemology that are no longer suited as an explanans of human nature in general, and homosexuality in particular.

In the realm of biological explanations, I pointed out the existence of two conserved structural features that act synergistically in order to block any chances of a fecund dialogue between humanities and biological sciences. First, the conception of homosexuality in humans as a homologous trait to homosexual behaviors in other animals, on the one hand, and, second, conceiving homosexuality as a normative phenomenon that nonetheless can be grounded in biological causes that structure the consciousness of homosexual subjects, on the other.

I also claimed that these conserved structural features, although consistent with an evolutionary thinking, interfere with the possibility of fully understanding the constructivist challenge. This is so because these conserved features offer a trans-historical view on homosexuality that ignores the complexities of the human subject.

This constructivist challenge has two more attributes. Both emanate from a criticism that deconstructs the supposed validity and objectivity of the evidence and the causal narrative erected upon it through a dialectic analysis of the relationship between the subject and the object. The ultimate goal of the constructivists is to restore the complexity of the subject and, therefore, advance the possibility of searching for a different type of explanation.

Nevertheless, my analysis of the structural features of the biological explanations and the constructivist counter-explanations also led me to the belief that, although biologists do not fully understand the intricacies of subjects, neither constructivists understand the facticity of evolution and the challenge that it implies.

If so, then the subject might be the right target of explanation. And, if so, constructivists might be right about the uniqueness of human homosexuality as a modern, western phenomenon explainable in terms of subjectivities and identities that mold and are molded by desires and institutions. But, if they are, evolution is not expendable because now we are facing a most intriguing question: How is that we humans became subjects?

In my view the resolution of these tensions requires reframing the question in order to abandon the conserved structural elements that anchor research. Eventually, this should takes us into a new framework in which we can talk of an Evolutionary Social Constructivism in which human nature is not represented anymore as the negation of our cultural complexity but as what grants us that very cultural complexity.

\section{Acknowledgements}

I would like to thank Edna Suárez for her support, advices and encouragement. Also, I would like to thank Rasmus Winther for his support and advices. Finally, I would like to thank the seminars of Philosophy of Biology at UNAM and UAM-C and the scholarship provided by DGAPA-UNAM.

\section{REFERENCES}

Bagemihl, B. (1999). Biological exuberance: Animal homosexuality and natural diversity. New York, NY: St. Martin's Press.

Butler, J. (1993). Bodies that matter: On the discursive limits of "sex". New York, NY: Routledge.

Byne, W. (1994). The biological evidence challenged. Scientific American, 270, 50-55. doi:10.1038/scientificamerican0594-50

Craver, C. (2007). Explaining the brain: Mechanisms and the mosaic unity of neuroscience. London: Oxford University press.

Daston, L., \& Galison, P. (2010). Objectivity. Brooklyn, NY: Zone Books.

Dean, T., \& Lane, C. (2001). Homosexuality and psychoanalysis. Chicago, IL: The University of Chicago Press.

DeLamater, J., \& Shibley, H. J. (1998). Essentialism vs social constructionism in the study of human sexuality. The Journal of Sex Research, 35, 10-18. doi:10.1080/00224499809551913

Derrida, J. (2008). The animal that therefore I am. New York, NY: Fordham University Press.

Dickinson, N., Paul, C., \& Herbison, P. (2003). Same-sex attraction in a birth cohort: Prevalence and persistance in early adulthood. Social Science \& Medicine, 56, 1607-1615. doi:10.1016/S0277-9536(02)00161-2

Esteban, J. M., \& Martínez, S. (Eds.) (2008). Normas y Prácticas en la Ciencia. Mexico City: UNAM-IIF's.

Fausto-Sterling, A. (2000). Sexing the body: Gender politics and the construction of sexuality. New York, NY: Basic Books.

Ferla, L. (2004). Gregorio Marañón y la apropiación de la homosexualidad por la medicina legal brasileña. Frenia, 4, 53-76.

Foucault, M. (1977). Historia de la sexualidad. Mexico City: Siglo XXI Editores.

Griffiths, P. E., \& Gray, R. D. (1994). Developmental systems and evolutionary explanation. Journal of Philosophy, 91, 277-304. doi:10.2307/2940982

Griffiths, P. (2011). Our plastic nature. In S. B. Gissis, \& E. Jablonka (Eds.), Transformations of lamarckism: From subtle fluids to molecular biology (pp. 319-330). London: The MIT Press.

Habermas, J. (1999[1981]). Teoría de la Acción comunicativa. Racionalidad de la acción y racionalización social. Bogotá: Grupo Santillana.

Hacking, I. (2001). Degeneracy, criminal behavior, and looping. In D. Wasserman, \& R. Wachbroit (Eds.), Genetics and criminal behavior (pp. 141-168). Cambridge: Cambridge University Press. doi:10.1017/CBO9781139173162.006

Hamer, D., Hu, S. Magnuson, V., Hu, N., \& Pattatucci, A. (1993). A linkage between DNA markers on the $\mathrm{X}$ chromosome and Male Sexual Orientation. Science, 261, 321-327. doi:10.1126/science.8332896

Haraway, D. (1989). Primate visions: Gender, race, and nature in the world of modern science. New York, NY: Routledge, Chapman and Hall, Inc.

Hebb, D. O. (1953). Heredity and environment in mammalian behaviour. The British Journal of Animal Behaviour, 1, 43-47. 
doi:10.1016/S0950-5601(53)80053-5

Heidegger, M. (1971[1927]). El Ser y El Tiempo. Mexico City: Fondo de Cultura Económica.

Hu, S., Pattatucci, A. M. L., Patterson, C., Li, L., Fulker, D., Cherny, S., Kruglyak, L., \& Hamer, D. (1995). Linkage between sexual orientation and chromosome Xq28 in males but not in females. Nature Genetics, 11, 248-256. doi:10.1038/ng1195-248

Hull, D. (1965). The effect of essentialism on Taxonomy: Two thousand years of Stasis I. British Journal for the Philosophy of Science, 15, 314-326. doi:10.1093/bjps/XV.60.314

Hutchinson, G. E. (1959). A speculative consideration of certain forms of sexual selection in Man. American Naturalist, 93, 81-93. doi:10.1086/282059

King Dávalos, P. (2008). De las normas implícitas en las prácticas lingüísticas a las normas implícitas en prácticas epistémicas. In Esteban \& Martínez (Eds.), Normas y prácticas en la ciencia (pp. 61-80). Mexico City: UNAM.

Kirby, J. (2003). A new group-selection model for the evolution of homosexuality. Biology and Philosophy, 18, 683-694. doi:10.1023/A:1026321628276

Kuhn, T. S. (1977). Objectivity, value judgment, and theory choice. In T. S. Kuhn (Ed.), The essential tension (pp. 320-339). Chicago: The University of Chicago Press.

Latour, B. (1992). Ciencia en Acción. Cómo seguir a los científicos e ingenieros a través de la sociedad. Barcelona: Editorial Labor.

Latour, B. (1999). Pandora's Hope: Essays on the reality of science studies. Cambridge, MA: Harvard University Press.

LeVay, S. (1991). A difference in hypothalamic structure between heterosexual and homosexual men. Science, 253, 1034-1037. doi:10.1126/science.1887219

LeVay, S., \& Hammer, D. (1994). Evidence for a biological influence in Male homosexuality. Scientific American, 270, 44-49. doi:10.1038/scientificamerican0594-44

Longino, E. H. (2002). The fate of knowledge. Princeton, NJ: Princeton University Press.

Marañon, G. (1960). Ensayos sobre la vida sexual. Madrid: EspasaCalpe.

Marks, J. (2012). Evolutionary ideologies. In A. Poiani (Ed.), Pragmatic evolution: The applications of evolutionary theory (pp. 297312). Cambridge: Cambridge University Press.

Martínez, M., \& Moya, A. (2011). Natural selection and multilevel causation. Philosophy \& Theory in Biology, 3, e212.

Mayr, E. (1993). Proximate and ultimate causations. Biology and Philosophy, 8, 93-94. doi:10.1007/BF00868508

Mc Manus, F. (2009). Rational disagreements in phylogenetics. Acta Biotheoretica, 57, 99-127. doi:10.1007/s10441-009-9072-2

Mc Manus, F. (2010). La Homosexualidad a la luz de la Filosofía de la Ciencia: Mecanismos Biológicos, Subjetividad y Poder. PhD Thesis, Mexico City: UNAM.

Mc Manus, F. (in Press). Las Bases neuroendocrinas de la Homosexualidad y la atomización mecanística del cuerpo.

Millikan, R. G. (1984). Language, thought, and other biological categories: New foundations for realism. London: The MIT Press.

Muscarella, F., Fink, B., Grammer, K., \& Krik-Smith, M. (2001). Homosexual orientation in males: Evolutionary and ethological aspects. Neuroendocrinology Letters, 22, 393-400.

Oyama, S., Griffiths, P., \& Gray, R. (2001). Cycles of contingency: Developmental systems and evolution. London: The MIT Press.

Pillard, R. (1997). The search for a genetic Influence on Sexual orientation. In V. A. Rosario (Ed.), Science and homosexualities (pp. 226241). New York: Routledge.

Poiani, A. (2010). Animal homosexuality: A biosocial perspective. Cambridge: Cambridge University Press.

Prieur, A. (2008). La casa de la mema: Travestis, locas y machos. Mexico City: PUEG-UNAM.
Rahman, Q., \& Wilson, G. (2003). Born gay? The psychobiology of human sexual orientation (Review). Personality and Individual Differences, 34, 1337-1382. doi:10.1016/S0191-8869(02)00140-X

Rendall, D., \& Di Fiore, A. (2007). Homoplasy, homology, and the perceived special status of behavior in evolution. Journal of Human Evolution, 52, 504-521. doi:10.1016/j.jhevol.2006.11.014

Rieppel, O. (2005). Modules, kinds, and homology. Journal of Experimental Zoology, 304B, 18-27. doi:10.1002/jez.b.21025

Roof, J. (1992). Hypothalamic criticism: Gay Males studies and male feminist criticism. American Literary History, 4, 355-364. doi:10.1093/alh/4.2.355

Rosario, V. A. (1997). Homosexual bio-histories: Genetic nostalgias and the quest for paternity. In V. A. Rosario (Ed.), Science and Homosexualities (pp. 89-107). New York: Routledge.

Roughgarden, J. (2004). Evolution's rainbow: Diversity, gender, and sexuality in nature and people. Los Angeles, CA: University of California Press.

Roughgarden, J. (2009). The genial gene: Deconstructing Darwinian selfishness, cooperation and the evolution of Sex. Los Angeles, CA: University of California Press.

Rouse, J. (1994). Engaging science: How to understand its practices philosophically. New York, NY: Cornell University Press.

Rouse, J. (2002). How scientific practices matter: Reclaiming philosophical naturalism. Chicago, IL: Chicago University Press.

Savic, I., Berglund, H., \& Lindström, P. (2005). Brain response to putative pheromones in homosexual men. PNAS, 102, 7356-7361.

Savic, I., Berglund, H., \& Lindström, P. (2008). PET and MRI show differences in cerebral asymmetry and functional connectivity between homo- and heterosexual subjects. PNAS, 105, 10273-10274. doi:10.1073/pnas.0407998102

Schmitt, F. (Ed.) (1994). Socializing epistemology: The social dimensions of knowledge. New York, NY: Roman and Littlefield.

Sober, E., \& Wilson, D. S. (1998). Unto others: The evolution of psychology and unselfish behavior. Cambridge, MA: Harvard University Press.

Sterelny, K. (2001). The evolution of agency and other essays (Cambridge Studies in Philosophy of Biology). Cambridge, MA: Cambridge University Press.

Striedter, G. F. (2004). Principles of brain evolution. Sunderland, MA: Sinauers Associates, Inc.

Sullivan, N. (2003). A critical introduction to Queer Theory. New York, NY: New York University Press.

Swaab, D., Chung, W., Kruijver, F., Hofman, M., \& Ishunina, T. (2001). Structural and fuctional sex differences in the human hypothalamus. Hormones and Behavior, 40, 93-98. doi:10.1006/hbeh.2001.1682

Vidal, F. (2006). The sciences of the soul: The early modern origins of psychology. Chicago, IL: University of Chicago Press.

Weiss, G. (1999). Body images: Embodiment as intercorporeality. London: Routledge.

Wilson, D. S. (2005). Evolutionary social constructivism. In J. Gottschall, \& D. S. Wilson (Eds.), The literary animal: Evolution and the nature of narrative (Rethinking Theory) (pp. 20-37). New York: Northwestern University Press.

Winther, R. (2006). On the dangers of making scientific models ontologically independent: Taking Richard Levins’ warnings seriously. Biology and Philosophy, 21, 703-724. doi:10.1007/s10539-006-9053-7

Winther, R. (2009). Character analysis in cladistics: Abstraction, reification, and the search for objectivity. Acta Biotheoretica, 57, 129162. doi:10.1007/s10441-008-9064-7

Yamamoto, D., Ito, H., \& Fujitani, K. (1996). Genetic dissection of sexual orientation: Behavioral, cellular, and molecular approaches in Drosophila melanogaster. Neuroscience Research, 26, 95-107. doi:10.1016/S0168-0102(96)01087-5 